\title{
Analysis of the $\mathrm{O} 2 \mathrm{O}$ marketing model about "old network"
}

\author{
website \\ Wenrong Jiang \\ School of Computer and Information, Shanghai Polytechnic University, China \\ wrjiang@sspu.edu.cn
}

\begin{abstract}
The Old Network is a portal website used for second-hand information in local life. It has rich information on second-hand trade and serves for life station around the country. Firstly, this paper gives some advice on marketing of the Old Network by SWOT analysis of the Old Network e-commerce. Meanwhile, we plan some competitive projects of the Old Network, such as public donation and turning waste into treasure. We also analyze the market impact of marketing activity. Marketing methods raised in this paper have positive effect on marketing of the Old Network and standardization of second-hand information trade.
\end{abstract}

Key words: O2O; marketing model; analysis of cases; e-commerce; old network

\section{Introduction}

With the rapid development of the Internet, the development of e-commerce is more and more mature. ${ }^{1,2}$ Second-hand goods trading website is featured in today's e-commerce transactions and full of categories. According to the scope of business, it can be divided into two categories. One is to trade only second-hand information, the other is to provide full online trading services, from information to the payment and settlement. Selecting a representative for the Old Network, analysis of a case study approach to its development, strengths and weaknesses, market conditions, can effectively understand the business processes of secondary trading websites, business model, market conditions, and other information.

The Old Network (http://www.Jiu6.com) is a national second-hand information portal. Since its establishment in 2009, the Old Network in Shijiazhuang, Hebei province took the lead, quickly spread to the local daily life. After a year of development, the old Web service has covered second-hand material in all areas of daily life. For a mature and familiar experience and organizational structure, the company will begin service in 343 main cities in the country, effort to build China's second-hand thrift and related fields, and the most authoritative and most influential online trading platform. 


\section{Development around the world}

With the development of e-commerce market at home and abroad and the improvement of people's living standards, second-hand items also have a lot of idle, which naturally lead to the development of secondary trading market at home and abroad.

At abroad, e-commerce has a relative perfect development, ${ }^{2}$ but second-hand merchandise trading abroad of website and no is strong of targeted, while, some abroad second-hand trading application of business mode also effort to explore among. Thus, mature development of second-hand trading is up of also not too more, abroad second-hand merchandise of trading main also is in several has mature of traditional e-commerce website, like eBay, Amazon etc.

E-commerce started comparatively late in China, but the momentum is very strong. As a result, the secondary market is growing rapidly. ${ }^{3}$

In China, there are a large number of commodity trading websites. These websites can basically be divided into second-hand housing, cars, daily necessities, books and other major categories. According to the secondary trading service, which probably can be divided into two categories, one is to serve as a third party information platform. These websites are only responsible for the release of secondary commodity transaction information. The other is a platform for providing services directly. These websites offer services ranging from information release to payment and settlement. Whether it is domestic or abroad, and whether application is B2C mode or C2C mode, the maximum problem facing second-hand trading network is quality of merchandise and inaccurate information of merchandise, because platforms are not strict of quality certification system and institutions, and no quality certification of standard. Trading risk also increases because of high depreciation rate and damaged rate.

\section{Analysis of SWOT}

We use SWOT analysis (strengths, weaknesses, opportunities, and threats) here to analyze the Old Network.

\subsection{Advantage}

Competitive advantage is the organizational structure of the internal factors, including favourable competitive situation, adequate financial resources, a good corporate image, technology, economies of scale, product quality, market share, cost advantage, advertising campaign, and so on. ${ }^{4}$

The Old network is a platform specializing in second-hand merchandise trading, compared with YiQu and TaoBao, which have more professional of second-hand platform. Old Network of second-hand merchandise of service is abundant and covers real estate, vehicles, digital products, home, ticketing, many big class. However, due 
to the Old Network is only responsible for releasing merchandise information, and not provides trading, while oriented of local life service, is big degree Shang reduced has due to second-hand trading and brings of market risk, while the Old Network has treasure, environmental project and many public project, This can be brought to the site's advantages as a site a high reputation.

\subsection{Disadvantage}

Competitive disadvantage is a comparative disadvantage in the competition, also within the organization, including: the aging equipment, poor management, lack of key technologies, research and development to develop backward, the shortage of funds, mismanagement, squeeze, less competitive.

The Old network displayed many serious problems in propaganda marketing because the Old Network involved business service category is not common. This causes much uneven and useless information emerges. Increasing prices have user select time-cost consumption, causing website image fell, and also having website of overall style design also and no is good to with progress of technology, from on the and pulled low has website of image.

\subsection{Opportunity}

Opportunity is an external factor of the organization, including: new products, new markets, new requirements, and market barriers, competitor failures and etc. ${ }^{5}$

The Old Network has a very large number of users and the huge second-hand commodity trading information, and with the cultivation of good habits of frugality, second-hand commodity trading will become more and more. It used to carry out environmental projects and public welfare projects such as clothing donations can also be donated as image and awareness of the best ways to improve the Web site.

\subsection{Threats}

Threats are external factors of organization, ${ }^{6}$ including: new rivals, substitute products increase, markets, changes in industry policy, the recession and customer preferences change, and so on.

Similar second-hand e-commerce website in China rapid development, coupled with many of the traditional e-commerce giants, like Alibaba and other local service providers on the Internet opened a second-hand goods transactions, market share is a little bit of the old network is compressed.

\section{Solutions}

The Old Network imperative is the standard website product information published, stringent enforcement actions against illegal mix of information, affecting the purity 
of website information, website information standardization, producing information effectively to prevent spam flooding Web sites on the Internet, or causing inconvenience to commodity exchange, impact on the user experience.

Secondly, a lot of online and offline promotions increase website visibility effectively, as the biggest site for second-hand goods in China, the Old Network penetration is very low in the crowd. Therefore, core network next strategy should be based on the promotion.

In addition, the Old Network has a very large project that has a core competence, such as "treasure" in environmental protection projects, "clothing family welfare" projects, network should guarantee the quality of product line business case, stepped up in these projects as a competitive advantage, improve development efforts and propaganda.

After product operation and product quality enhancement, offline and online publicity, promotion, network users saw steady growth over time.

There are some strategies the Old Network can take in marketing.

(1) Virus-like marketing. Includes email, online advertising, marketing, and is characterized by low cost and short marketing time, the effect is obvious, the marketing goal is to get new customers and effective marketing tool.

(2) Permission marketing. Permission marketing requirements for advertising content and consumers are highly relevant, such as sweepstakes with incentives, and features once consumer permission to obtain consumer data with a high degree of accuracy.

(3) Keyword markseting. To promote enterprise through search engine optimization, which is characterized by low cost and good publicity.

(4) Marketing in virtual community. Features of virtual communities with high traffic, and focus are e-commerce sites good marketing.

(5) Marketing by Blogs, micro-blogging, weixin. This form of marketing can greatly broaden the network's brand image, and create a quality customer experience, provides businesses with products correspond to the substance.

Meanwhile, public projects can do cause-related marketing. Public marketing is for people's survival and development, and social progress as a starting point, by means of public service activities to communicate with consumers, welfare effects at the same time, so that consumers have of a company's product or service preferences, and improve brand visibility and reputation of marketing practices.

In recent years, cause marketing is more and more widely used in the national marketing campaign, with public sentiment, establish long-term friendly relations, enhance their visibility and reputation, unique affinity marketing, which get more and more enterprises favour, they have enthusiastically charity activities carried out in the various kinds of public utilities in order to establish a good corporate image. ${ }^{[5]}$ Charitable or public interest, there is no essential difference, through these activities, 
on the one hand that corporate social responsibility, win public recognition, improve corporate reputation and enhance long-term competitiveness; on the message to the outside world in this enterprise has the strength of information, enhancing the confidence of employees and consumers. Community acts as a social PR activities through Pro Bono's move to establish a positive corporate image is the true meaning of cause marketing.

\section{Effect and results}

Strictly control the Web site information and after passing through the major online and offline marketing and advertising is expected to increase the number of users shown in the following figure.

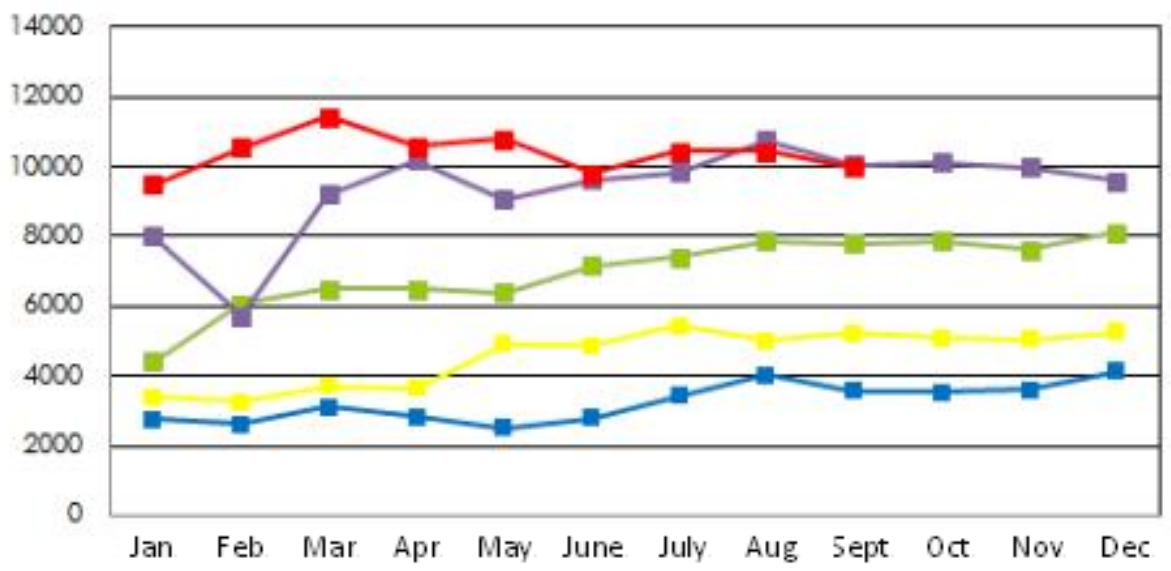

Fig. 1 - Growth of members

\section{Summary}

Obviously, second-hand goods transactions in e-commerce will develop further in the future. Web site marketing plays a vital role in the site's operation, so it used the impact would in future marketing efforts noticed in.

Because web site marketing plays an important role in operation of sites, it will have significant impact on the market.

\section{Acknowledgements}

This work is supported by the Key Disciplines of Computer Science and Technology of Shanghai Polytechnic University under Grant No. XXKZD1604.

\section{References}

1. Wenrong Jiang, Min Liu. Analysis and Exploration Undergraduate Students E-Commerce Business Model[J]. 2014 International Conference on Business, Economics and Management (BEM 2014), Hongkong, China, 2014(3) 3-8. 
2. Wenrong Jiang, Yingyan Liu. Analysis of the double 11 ouyeel business promotion effectiveness[C]. 2016 ISSGBM International Conference on Information, Communication and Social Sciences (ISSGBM-ICS 2016), Dubai, United Arab Emirates, Singapore Management and Sports Science Institute, October 8 (2016) 49-55.

3. Wenrong Jiang. Analysis of the E-commerce website-Lianliangou[C]. 2016 2nd International Conference on Electronics, Network and Computer Engineering(ICENCE2016), Yinchuan, China, Advances in Computer Science Research, Vol67. Auguest 13 (2016) 674-679.

4. Wenrong Jiang, Shiwei Li. Analysis of Xiaomi Tech's E-commerce model[J]. 2nd International conference on E-commerce and Contemporary Economic Development (ECED 2015), Nanjing, China, December 5-6 (2015) DEStech Publications, Inc. 196-200.

5. Wenrong Jiang, Jian Chen.Analysis of the wabsite-Hj operations[J]. 2015 3nd International Conference on Applied Social Science Research (ICASSR 2015), Limassol, Cyprus, October 4-5 (2015) 103-106.

6. Wenrong Jiang, Jian Chen.Traditional Enterprises Transformation and Strategy to Deal with E-Commerce[J]. 2015 4th International Conference on Physical Education and Society Management (ICPESM 2015), Singapore, December 6-7, 2015, Lecture Notes in Management Science 47 (2015(12)) 301-306. 